\title{
Building hazard maps of extreme daily rainy events from PDF ensemble, via REA method, on Senegal River Basin
}

\author{
J. D. Giraldo Osorio and S. G. García Galiano \\ Universidad Politécnica de Cartagena, Department of Civil Engineering, R\&D Group of Water Resources Management, \\ Paseo Alfonso XIII, 52, 30203, Cartagena, Spain
}

Received: 23 March 2011 - Published in Hydrol. Earth Syst. Sci. Discuss.: 15 April 2011

Revised: 2 November 2011 - Accepted: 16 November 2011 - Published: 29 November 2011

\begin{abstract}
The Sudano-Sahelian zone of West Africa, one of the poorest of the Earth, is characterized by high rainfall variability and rapid population growth. In this region, heavy storm events frequently cause extensive damage. Nonetheless, the projections for change in extreme rainfall values have shown a great divergence between Regional Climate Models (RCM), increasing the forecast uncertainty. Novel methodologies should be applied, taking into account both the variability provided by different RCMs, as well as the non-stationary nature of time series for the building of hazard maps of extreme rainfall events. The present work focuses on the probability density functions (PDFs)-based evaluation and a simple quantitative measure of how well each RCM considered can capture the observed annual maximum daily rainfall (AMDR) series on the Senegal River basin. Since meaningful trends have been detected in historical rainfall time series for the region, non-stationary probabilistic models were used to fit the PDF parameters to the AMDR time series. In the development of PDF ensemble by bootstrapping techniques, Reliability Ensemble Averaging (REA) maps were applied to score the RCMs. The REA factors were computed using a metric to evaluate the agreement between observed -or best estimated- PDFs, and that simulated with each RCM. The assessment of plausible regional trends associated to the return period, from the hazard maps of AMDR, showed a general rise, owing to an increase in the mean and the variability of extreme precipitation. These spatialtemporal distributions could be considered by Organization for the Development of the Senegal River (Organisation pour la mise en valeur du fleuve Sénégal, OMVS), in such a way as to reach a better balance between mitigation and adaptation.
\end{abstract}

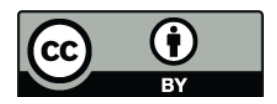

Correspondence to: S. G. García Galiano (sandra.garcia@upct.es)

\section{Introduction}

One of the areas hardest hit by the twentieth century climate change impacts, has been the densely populated Sahel (West Africa). Over the period 1990-2020, its population is expected to double, with projections of even higher growth for some cities in the Senegal River Valley (Cour, 2001). The climatic fluctuations in the Sahel have been devastating (famines, migrations, and slow economic growth), indicating the great vulnerability of the region (Lebel et al., 2009; Paeth et al., 2009). The study of the continuous rise in greenhouse gases emission, and the associated response of the climate, has received more attention for the region in recent years. Global warming has caused changes in rainfall patterns and, consequently, changes in the frequency and magnitude of extreme events (Labat et al., 2004; Huntington, 2006; Kundzewicz et al., 2007). Huntington (2006) points out that the evidence about the current and future intensifying of the hydrologic cycle is robust, and highlights the need to improve the ability of monitoring and predicting the impacts associated with the change of hydrologic regimes. In these conditions, the presumption of hydroclimatic stationarity cannot be guaranteed, due to the interaction of various drivers (land use and climate change, and population growth, among others). In concordance with the opinion of several authors (Milly et al., 2008; Villarini et al., 2010), nonstationary probabilistic models able to reproduce the variation with time of the parameters of selected probability density functions (PDFs) should be used.

In this sense, Regional Climate Models (RCMs) have become an important tool to improve the understanding of key processes involved in the description of climate mechanisms (Sánchez et al., 2009), for the simulation of plausible climate scenarios with an appropriate resolution for impact studies

Published by Copernicus Publications on behalf of the European Geosciences Union. 
at basin scale. Several authors have worked with climate models to simulate the trends in extreme rainfall patterns, especially in Europe (Kharin and Zwiers, 2005; Kharin et al., 2009; Kyselý and Beranová, 2009; Nikulin et al., 2011, among others). There are notable advances in the simulation of dynamics of West Africa Monsoon (WAM) using climate models (Fontaine et al., 2011; Paeth et al., 2011; Ruti et al., 2011).

However, the RCMs built for West Africa are still sensitive to physical parameterizations, spatial-temporal resolution and internal variability (Paeth et al., 2011). The RCMs exhibit differing levels of skill over different regions and hydrometeorological variables, making it difficult to identify the models with greater confidence. As a consequence, the climate projections and the estimation of uncertainties associated are better based on the combination of information provided by an ensemble approach from different RCMs simulations (Giorgi and Mearns, 2002; Paeth et al., 2011). The model ensemble allows a more precise description of uncertainties and weaknesses, as well as a probabilistic approach to future climate projections (Sánchez et al., 2009). Tebaldi and Knutti (2007) conducted a review of methodologies addressing the building of model ensembles, comparing their results for regional temperature projections. However, the error obtained from combining multiple models is, sometimes, the result of error compensation. A weighting of models, based on observations, could ameliorate this problem (Sánchez et al., 2009). To assign weights to different RCMs of an ensemble, several statistics are usually compared considering observed data.

However, the use of statistics as means and standard deviations does not allow the comparison of the entire distribution of the data, even when the evidence shows those observed changes in the extreme events (tails) are different in magnitude to those observed in the mean values. In addition, the change associated with extreme values is expected to have a higher impact on biophysical systems (Perkins et al., 2007; Tapiador et al., 2009). This situation justifies questioning the ability of RCMs to simulate the distribution of observed probability of the hydrometeorological variables. There are several works about the estimation of PDFs associated with several hydrometeorological variables from climate projections (Wigley and Raper, 2001; Giorgi and Mearns, 2003; Tebaldi et al., 2005; Giorgi, 2008; Buser et al., 2009). Establishing the best skill of a climate model for simulating the observed PDF of a variable implies that estimated projections with this model will have more confidence for future projections (Perkins et al., 2007; Sánchez et al., 2009). However, the ability to represent the present-day climate well does not seem to be enough to asseverate the skill to simulate the future climate climate (Giorgi and Mearns, 2003).

With regard to the above, the present study focuses on the assessment of change in the PDF of the annual maximum daily rainfall (AMDR) on the Senegal River Basin (West Africa), considering the nonstationarity of time series and building at site PDF using a weighted ensemble. The RCMs and observational datasets considered for the target basin are described in Sect. 2.

Section 3 describes the implementation of the Reliability Ensemble Average (REA) method proposed by Giorgi and Mearns (2002), for assessing the ability of the RCMs to reproduce the present-day climate while at the same time evaluating the convergence of different RCMs to a given forcing scenario. The score method proposed by Perkins et al. (2007), is applied to identify the skill scores of the RCMs in the PDF ensemble for each site. Previous studies in the region have considered ensemble RCMs to assess impacts on extreme rainfall events (García Galiano and Giraldo Osorio, 2011). In the work of these authors, the reliability factors were considered constant for the entire study area, and estimated only based on the bias analysis (by SmirnovKolmorov test) between the observed and simulated series of AMDR (in other words, without consideration of convergence criteria between the time series to the future). In the present study, the REA factors are estimated spatially distributed.

Finally, the PDF ensembles were considered to build maps of various statistical values associated with the distribution of AMDR on the target basin, for studying the plausible trends of AMDR (Sect. 4). The PDF ensemble for each site allows to obtain a measure of the change uncertainty. The results and discussion section presents a brief analysis of the maps constructed, and the key findings of the work.

\section{Target basin and datasets}

The target basin of the Senegal River, shared by Guinea, Mali, Senegal, and Mauritania, presents a strong decreasing gradient of rainfall in northerly direction (Fig. 1). The Organization for the Development of the Senegal River (Organisation pour la mise en valeur du fleuve Sénégal, OMVS), is the river basin organization in charge of the management and planning of water resources in the region.

With less than $200 \mathrm{~mm} \mathrm{yr}^{-1}$ in the north (Sahel), to more than $2000 \mathrm{~mm} \mathrm{yr}^{-1}$ in the south (headbasin), the rainfall seasonal cycle is unimodal (Sandholt et al., 2003). The basin corresponds to three eco-regions, Sahelian savanna (north), West Sudanian savanna, and Guinean forest savanna (south).

Observed daily rainfall grids compiled by the IRD (Institut de Recherche pour le Developpement; previously ORSTOM, France), with spatial resolution of $1^{\circ}$, have been used. These grids were previously considered in other studies in West Africa (Diedhiou et al., 1999; Janicot and Sultan, 2001; Messager et al., 2004; García Galiano and Giraldo Osorio, 2010; Karambiri et al., 2011). Six RCMs were selected, driven by different GCMs (Global Climate Models) for scenario A1B: GKSS/CLM (ECHAM5), METO-HC/HAD (HadCM3Q0), KNMI/RACMO (ECHAM5-r3), INM/RCA (HadCM3Q0), SMHI/RCA (HadCM3Q0), MPI/REMO 
(a)

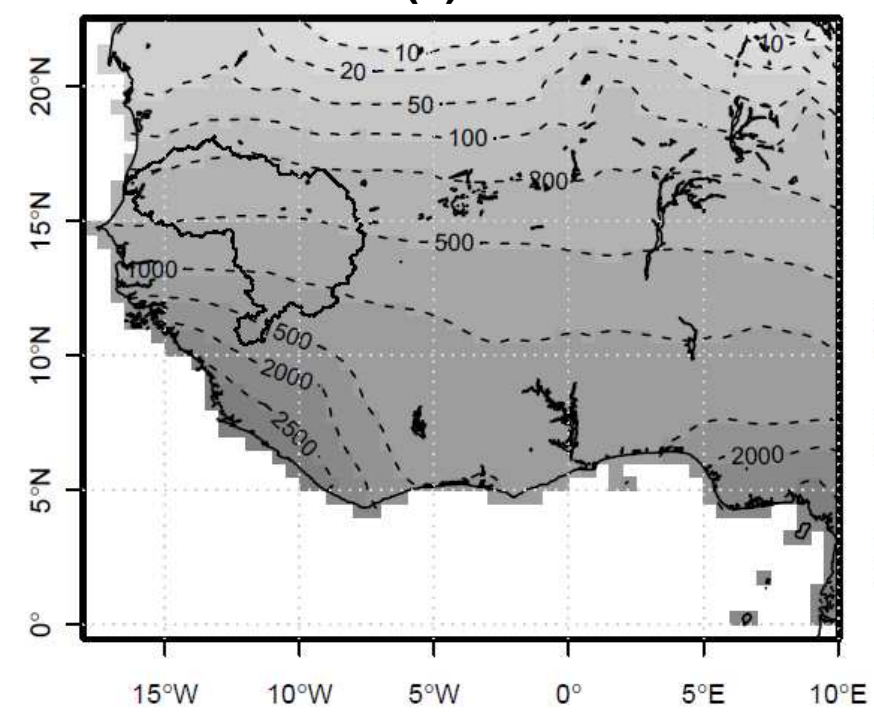

(b)

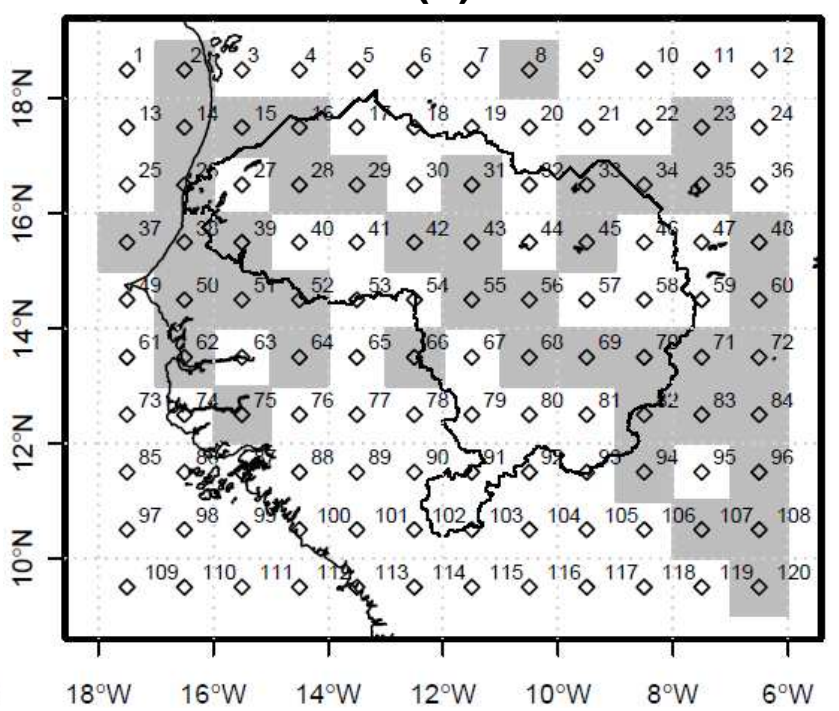

Fig. 1. Location of Senegal River Basin: (a) mean annual rainfall (mm) from Climate Research Unit database (CRU, University of East Anglia, Norwich, UK), over 1961-1990 period, and (b) sites selected for analyses, and The IRD sites are highlighted with gray squares.

(ECHAM5-r3), provided by the European ENSEMBLES Project (Christensen et al., 2009). The selection of RCM was based on its temporal coincidence with the IRD data (period 1970-1990), which enables the bias analysis. For the analysis, 120 sites on a regular grid of $1^{\circ} \times 1^{\circ}$ were selected. However, the spatial discontinuity of the IRD data constrains the bias analysis only on 43 of these sites (Fig. 1). The AMDR series were obtained from the observed and simulated daily rainfall grids, for the sites defined.

\section{Methodology}

A critical need in the research of climate change impacts focuses on quantifying the uncertainty associated with future climate projections. The results of impacts studies on hydrometeorological extremes and runoff in the study region, have shown a considerable divergence (García Galiano and Giraldo Osorio, 2010; Karambiri et al., 2011), which increases the uncertainty in predicting climate change at regional level using RCMs (Giorgi and Mearns, 2002). Several authors have contrasted results from RCMs to presentday data, trying to explain the dynamics of WAM, and interaction with precipitation. Among them, Sylla et al. (2009) worked with precipitation and temperature from ICTPRegCM3 RCM nested in both reanalysis data and ECHAM5 GCM simulations, and observed data from Climate Research Unit database (CRU, University of East Anglia, Norwich, UK); and Sylla et al. (2010b) analyzed intraseasonal and interannual variability of rainfall taking into account the same RCM driven by reanalysis data. The performance of the RCM, considering several observed datasets, was eval- uated by Sylla et al. (2010a) for seasonal mean climatologies, annual cycle and interannual variability over Africa. They found biases from the regional model as well as those brought through the boundary forcing, and have concluded that a larger set of RCMs and GCMs data comparisons could be better for general applicability.

Since it is not possible to conclude which model seems to be the most reliable, a comprehensive assessment of climate change projections needs to be based on the information provided by the RCM ensemble approach to simulate the variability of the rainfall, according to Giorgi and Mearns (2002). Based on these premises, the GAMLSS (Generalized Additive Models for Location, Scale and Shape) tool, proposed by Rigby and Stasinopoulos (2005), is applied to simulate the nonstationarity of the PDF of maximum rainfall in each site. The GAMLSS approach corresponds to semi-parametric regression models (Rigby and Stasinopoulos, 2005; Stasinopoulos and Rigby, 2007). In the present work, four theoretical probability distributions of two parameters were considered: Gumbel (GU), Gamma (GA), Lognormal (LN), and Weibull (WEI). Several previous studies have applied GAMLSS for modeling nonstationary extreme hydrometeorological time series (Villarini et al., 2009; Karambiri et al., 2011), considering similar PDFs.

In the next section, the methodology for weighting the RCMs using the REA factors (Giorgi and Mearns, 2002), and the score proposed by Perkins et al. (2007) considered for assessing PDFs agreements, are introduced. Finally, the PDF ensemble methodology is explained. 


\subsection{Reliability Ensemble Averaging (REA) method and Perkins score}

The REA method provides a measure of reliability, average and uncertainty range of simulated climate change from ensembles of different atmosphere-ocean general circulation models and RCMs (Giorgi and Mearns, 2002). Previous studies have used the REA method to evaluate the performance of climate models (Giorgi and Mearns, 2003; Bark et al., 2010; Dominguez et al., 2010; Mote and Salathé, 2010; Räisänen et al., 2010).

The method considers two criteria to estimate the model reliability factor $-R$ in Eq. (1). The first of them, model performance criterion $\left(R_{\mathrm{B}}\right)$, considers the performance of the model in reproducing present-day climate. The second one, model convergence criterion $\left(R_{\mathrm{D}}\right)$, evaluates the convergence to the "best estimated response" or REA average in the future climate projections. For reaching high reliability for a given RCM, both criteria should be met in Eq. (1). Giorgi and Mearns (2002) define the reliability factor for model $i$ as follows:

$R_{i}=\left[\left(R_{\mathrm{B}, i}\right)^{m} \times\left(R_{\mathrm{D}, i}\right)^{n}\right]^{[1 /(m \times n)]}$

where the parameters $m$ and $n$ are criterion weights. In this work, we assume $m=n=1$, giving equal weight to both criteria.

For estimation of the $R_{\mathrm{B}}$ and $R_{\mathrm{D}}$ parameters (Eq. 1), the Perkins score method (Perkins et al., 2007) was used. The Perkins score is a simple quantitative measure of the degree of agreement between the PDFs obtained from the RCMs and that observed from the data. This metric measures the common area between the two curves of the PDFs.

The Perkins score has been applied by several authors to assign weights to different climate models of an ensemble, for the analysis of several hydrometeorological variables (Perkins and Pitman, 2009; Boberg et al., 2009, 2010; Smith and Chandler, 2010).

In the case of the estimation of model performance criterion $R_{\mathrm{B}}$, the cumulative distribution functions $(\mathrm{CDFs})$ were built from observed data and from RCMs over the 19701990 time period. For the assignment of a cumulative probability to each value in the ordered series, the inverse of the Weibull equation was used.

For the model convergence criterion $R_{\mathrm{D}}$, the difficulty is that there is no AMDR PDF known for future climate. According to Giorgi and Mearns (2002), an iterative process is followed to obtain the estimated PDF and therefore to estimate $R_{\mathrm{D}}$. The estimated PDF is built using bootstraping techniques with $N=1000$ data, considering the simulated series for the models between 2021-2050 (30 yr). Initially, the reference PDF is built by assigning equal skill scores to all RCMs (this is, each model consists of $1000 / 6 \approx 167$ data, obtained from sampling with replacement from the simulated series of $30 \mathrm{yr}$ ). Then, the distance of each RCM to the estimated PDF is calculated and consequently the assigned weights are readjusted. This procedure converges quickly after some iterations. It should be noted that the PDF built in this way is only an estimate of the distribution of the AMDR of future climate projection. The REA average does not represent the actual climate response to the climate forcing scenarios, however the REA average represents the best estimate of this response (Giorgi and Mearns, 2002, 2003).

The values of $R_{\mathrm{B}}, R_{\mathrm{D}}$ and $R$ are estimated in the sites where the IRD is available (Fig. 1). Then, these values are interpolated (using the method of inverse distance), and the spatial distributions of the reliability factors (Fig. 2) are obtained for the selected RCMs.

According to Giorgi and Mearns (2002, 2003), the likelihood associated with a simulated change for the $\mathrm{RCM}_{i}$ is proportional to the model reliability factor $R_{i}$. In this, the results of models with higher reliability factor are more likely to occur. The normalized reliability factors, $P m$ in Eq. (2), can be interpreted as this likelihood associated with each RCM. Several authors (Tebaldi et al., 2005; Tebaldi and Knutti, 2007), have shown that the normalized reliability factors are analogous to the accuracy factors defined in their ensembles built by Bayesian approaches. The likelihood $P m$ for each RCM is defined as follows (Giorgi and Mearns, 2003):

$$
P m_{i}=\frac{R_{i}}{\sum_{1}^{N} R_{j}}
$$

Maps algebra was used to build the $P m$ raster, using the interpolated maps of $R$. The Pm maps (Fig. 2) allowed building the PDF ensembles in sites where the IRD data was not available, e.g. the south part of the domain.

\subsection{Calculation of PDF ensemble}

The GAMLSS adjustment to various series of AMDR in each site predicts trends that differ in magnitude and sign, depending on the RCM and site considered. As an example, the temporal variation of the AMDR PDF is represented with curves for different percentiles $(5,10,25,50,75,90$, and $95 \%$ ), applying GAMLSS to the six RCMs selected for site 16 (Fig. 3). The goodness of fit to the statistical model was assessed, considering the normality of the residuals, visual inspections of the qq-plots and the worm plot (not shown), according to the methodology presented by van Buuren and Fredriks (2001).

Therefore, for the building of the PDF ensemble in each site, greater weight was given to RCMs with high value of normalized reliability factor, using bootstrapping techniques (Efron and Tibshirani, 1993). Once the Pm maps were obtained, the PDF ensembles are built on each site of the study region. Random subsamples of size $N=10000$ were built, considering the RCM in proportional fashion to its normalized reliability factor (e.g. on site 16, 1550 values from GKSS/CLM, 1330 from METO-HC/HAD, and so on). To obtain the evolution of the probability distribution of AMDR 

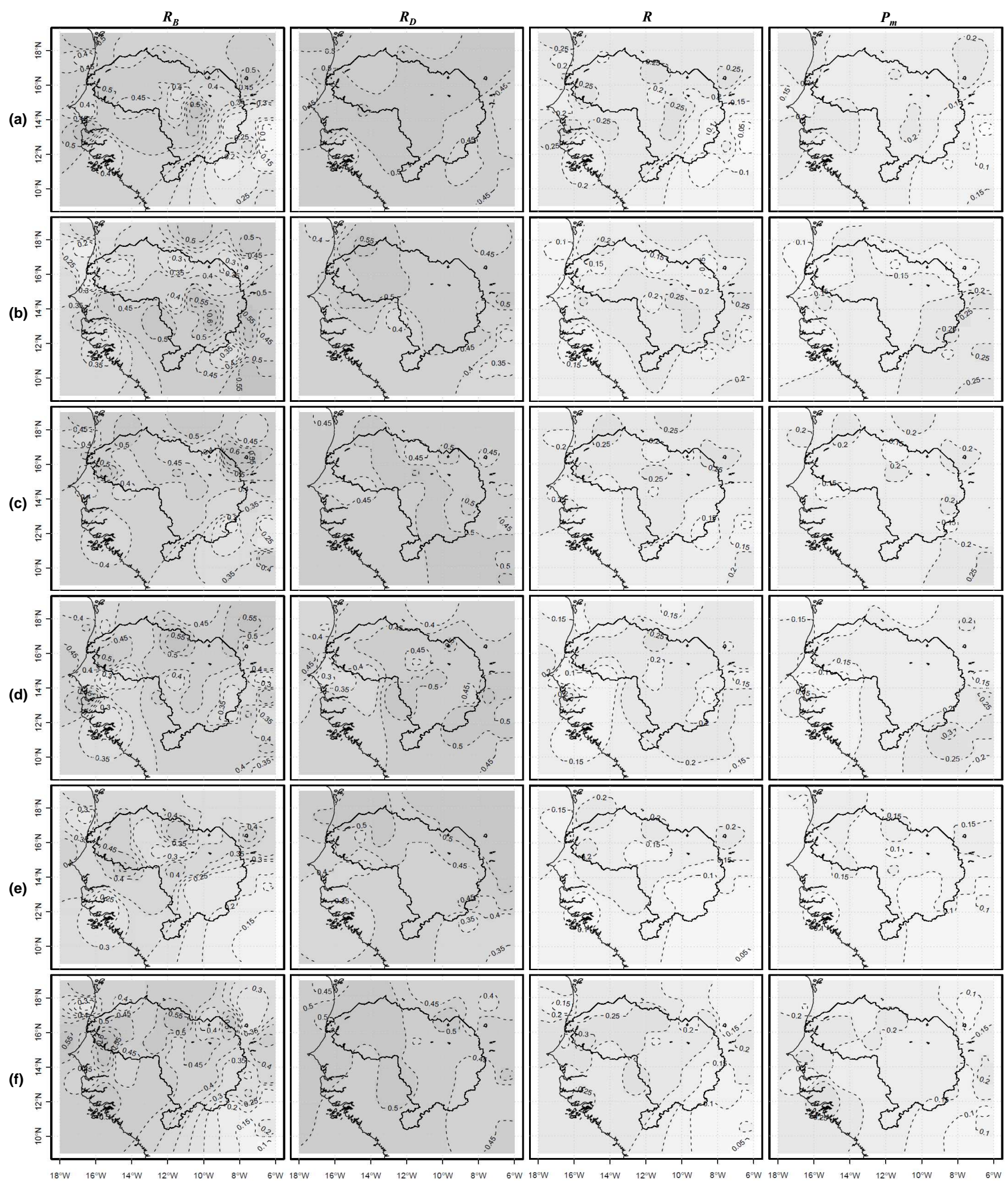

Fig. 2. Maps of RCM reliability factors $R_{\mathrm{B}}, R_{\mathrm{D}}, R$ and $P m$ : (a) GKSS/CLM, (b) INM/RCA, (c) KNMI/RACMO, (d) METNO-HC/HAD, (e) MPI/REMO, and (f) SMHI/RCA. 

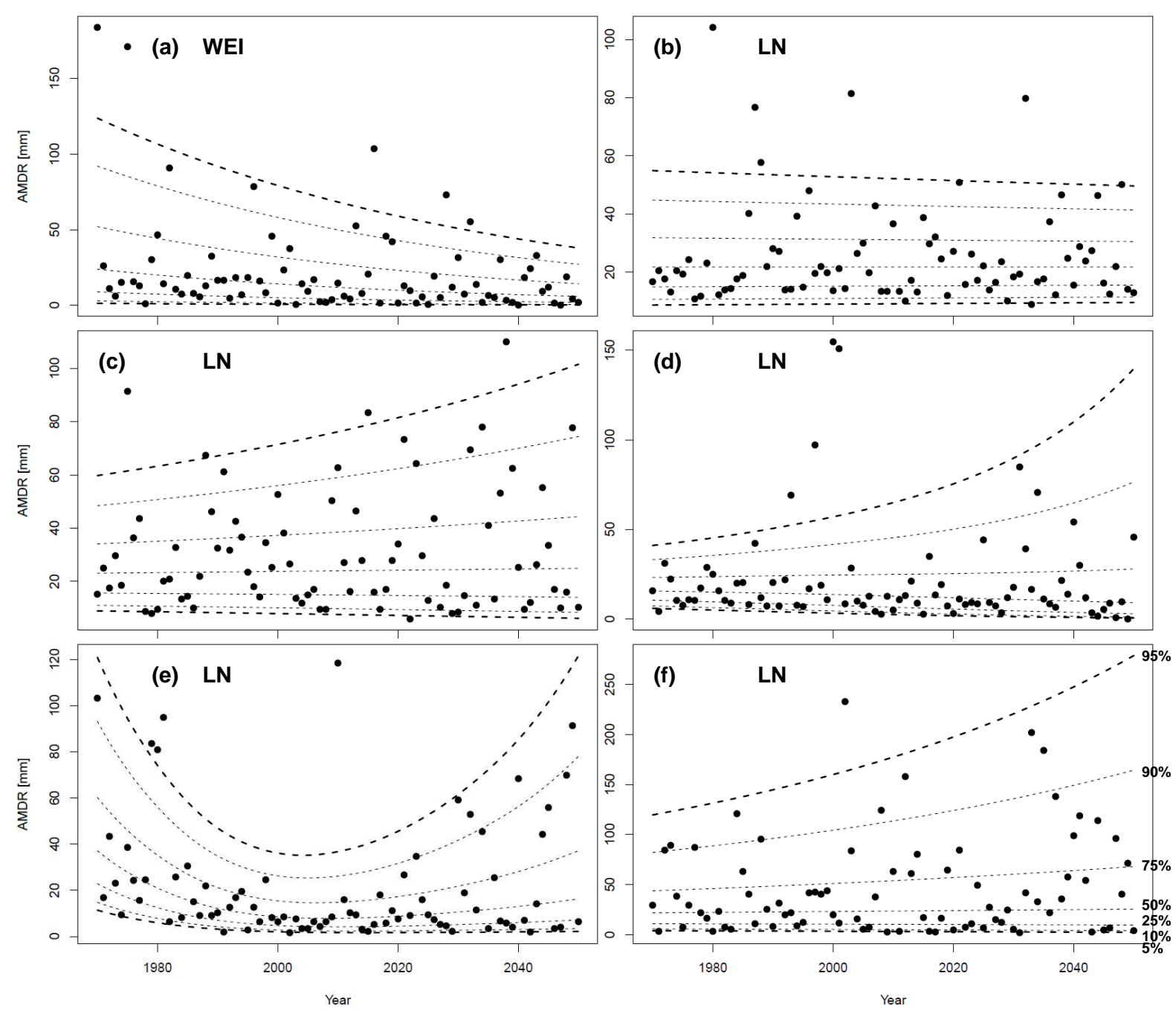

Fig. 3. GAMLSS analysis of AMDR (mm) for site 16 for several RCM: (a) GKSS/CLM, (b) METO-HC/HAD, (c) KNMI-RACMO, (d) INM-RCA, (e) SMHI/RCA, and (f) MPI-MREMO. The centile curves (5 to $95 \%$ ) are represented by dashed lines. It should be noted that the ordinate scale is automatically fixed.

in each site, PDF ensembles were constructed for each ten years in the period 1970-2050, and basic statistics (mean $\mu$ and standard deviation $\sigma$ ) and the quantiles for $5,10,25,50$, 75,90 , and $95 \%$ with their respective confidence intervals (95\% CI) were estimated.

From Fig. 4, for PDF ensemble in site 16, the difference in magnitude and sign of GAMLSS fit becomes more evident (e.g. the adjusted trend for the SMHI/RCA and MPI/REMO AMDR series indicates a plausible increasing, but with mean values of AMDR differences of about $30 \mathrm{~mm}$, while the GKSS/CLM presents a negative trend). Another feature of adjustment is that despite having the lowest value of the model performance criterion $R_{\mathrm{B}}$, the INM/RCA model presents the highest value of the model convergence criterion $R_{\mathrm{D}}$. Although this situation is not presented in all the sites analyzed, Giorgi and Mearns (2002) claimed that a large individual model bias does not imply a large model divergence.

\section{Results: maps of AMDR PDF statistics}

Once the statistics for the PDF ensemble at each site have been obtained for the period 1970-2050, these values were interpolated to generate maps depicting the spatio-temporal evolution of the AMDR distribution. In Fig. 5, the maps constructed for the mean, standard deviation, and for $90 \%$ and $95 \%$ quantiles ( $T r=10 \mathrm{yr}$ and $T r=20 \mathrm{yr}$, respectively) for 1990 and 2050, and their percentage difference, are presented. Using the Monte Carlo method based on bootstrapping with replacement (Efron and Tibshirani, 1993; Sánchez et al., 2009), applied to AMDR populations obtained from PDF ensemble, the sites where these differences were statistically significant for $95 \%$ bootstrap confidence intervals have been shown on difference maps with a dark grey square (Fig. 5). 


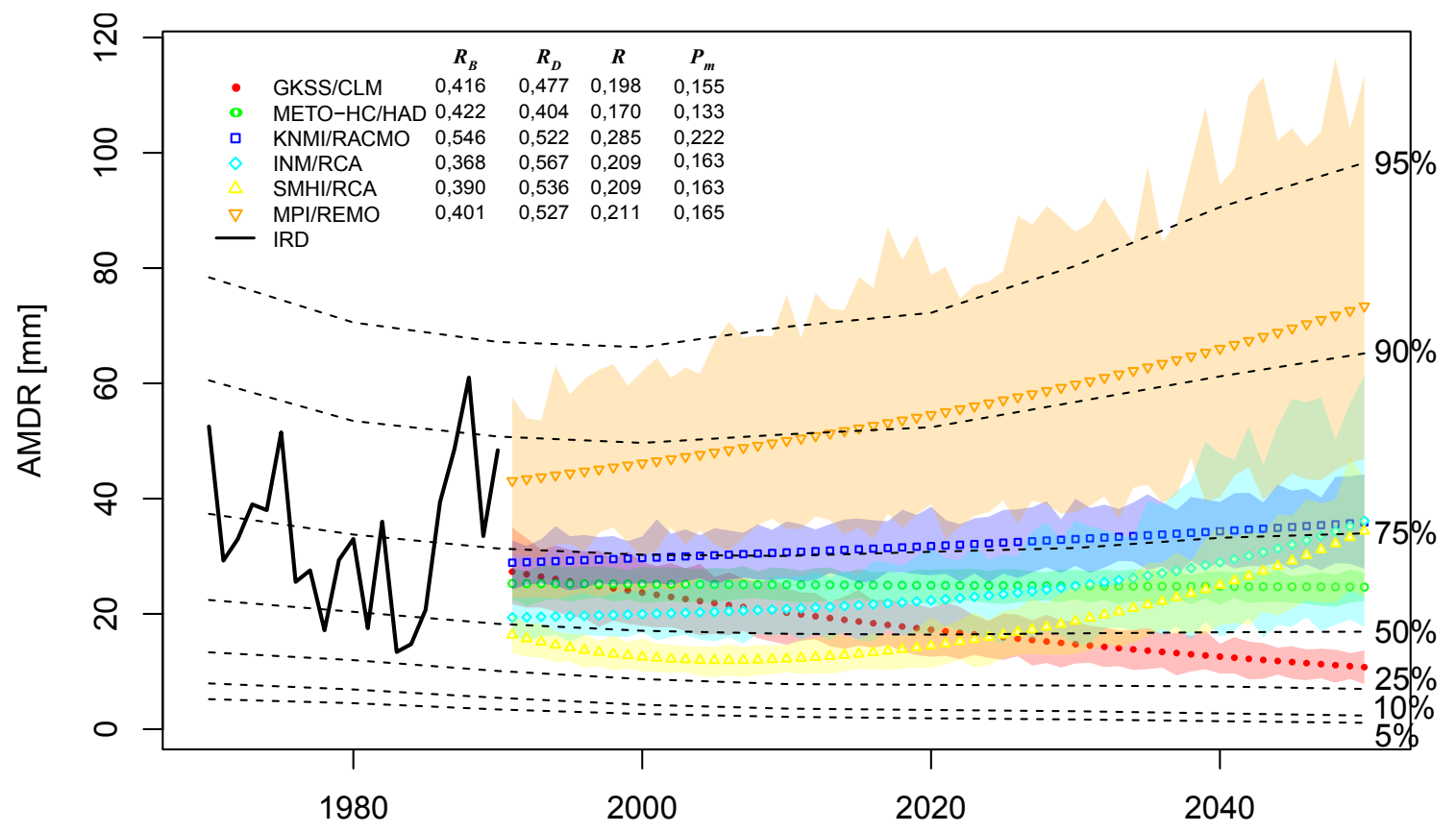

Time

Fig. 4. PDF ensemble on site 16. The dashed lines show 5 to $95 \%$ quantiles of PDF ensemble, and markers represent the RCM mean values obtained from the fitted PDF. The polygons show the mean variability in the period 1991-2050, using the $95 \%$ CI computed with bootstrapping. The IRD AMDR series in $1970-1990$ is presented as a solid line. The computed REA values $\left(R_{\mathrm{B}}, R_{\mathrm{D}}, R\right.$ and $\left.P m\right)$ used to build the PDF ensemble, are presented.

The maps constructed for $\mu$ (Fig. 5a) have a spatial structure that matches the latitudinal gradient of mean annual precipitation in the region (shown in Fig. 1), nonetheless the difference between them does not preserve this structure. Significant increase in $\mu$ is expected for 2050 in the Senegal River Valley and the upper basin, while in the Sahelian zone a decrease is projected, but it is not significant. In the Valley area, the expected increase in $\mu$ will be about $10 \mathrm{~mm}$, very similar to the increment for the upper basin, yet in the lower basin this represents a significant increase of over $30 \%$. The maps of $\sigma$ (Fig. 5b) retain the latitudinal gradient of rainfall maps, although less significantly than the $\mu$ maps. The difference between the two maps shows that in the lower basin a significant increase in $\sigma$ is projected for 2050, which could reach $80 \%(25 \mathrm{~mm})$, while in the upper basin the projected increase in this parameter hardly exceeds $25 \%$ (10 mm). Finally, the maps for $T r=10$ and $T r=20 \mathrm{yr}$ (Fig. 5c and d, respectively) show a clear latitudinal gradient, with a northward decrease in AMDR. A general increase in the AMDR associated with both return periods is expected for 2050, except at the northern edge of the basin and in some isolated areas of the study area within the Sudanian zone. With regard to $\operatorname{Tr}=10 \mathrm{yr}$, a significant increase is foreseen in the lower basin, where a difference of more than 20-25 mm was calculated between the reference years (30-40\%). On the other hand, a significant greater increase associated with $\operatorname{Tr}=20 \mathrm{yr}$ is estimated for the same region, where the difference is about 30-35 $\mathrm{mm}$ (40-50\%).

Previous studies in the area with similar objectives, have been developed. The maps obtained by García Galiano and Giraldo Osorio (2011) exhibit spatial trends very similar to those presented in the Fig. 5, however, they are numerically quite different. These authors estimated increases of about $40 \%$ for $\mu$, and up to $100 \%$ for $\sigma$, higher than calculated values in the present work, with more areas appearing with significant differences in their maps.

\section{Discussion and conclusions}

In order to distinguish the predicted changes in the severity and frequency of AMDR in the Senegal River Basin, plausible climate scenarios provided by RCMs and observed data were considered. The GAMLSS methodology and ensemble techniques allow to simulate the non-stationarity present in AMDR series for the study region.

Nevertheless, the good fit of the GAMLSS statistical model to simulated AMDR time series neither implies a proper coupling to the observed series from the IRD database, nor a proper convergence between the PDFs of AMDR future projections. In order to exploit all the information provided by the RCMs, a PDF ensemble is constructed 


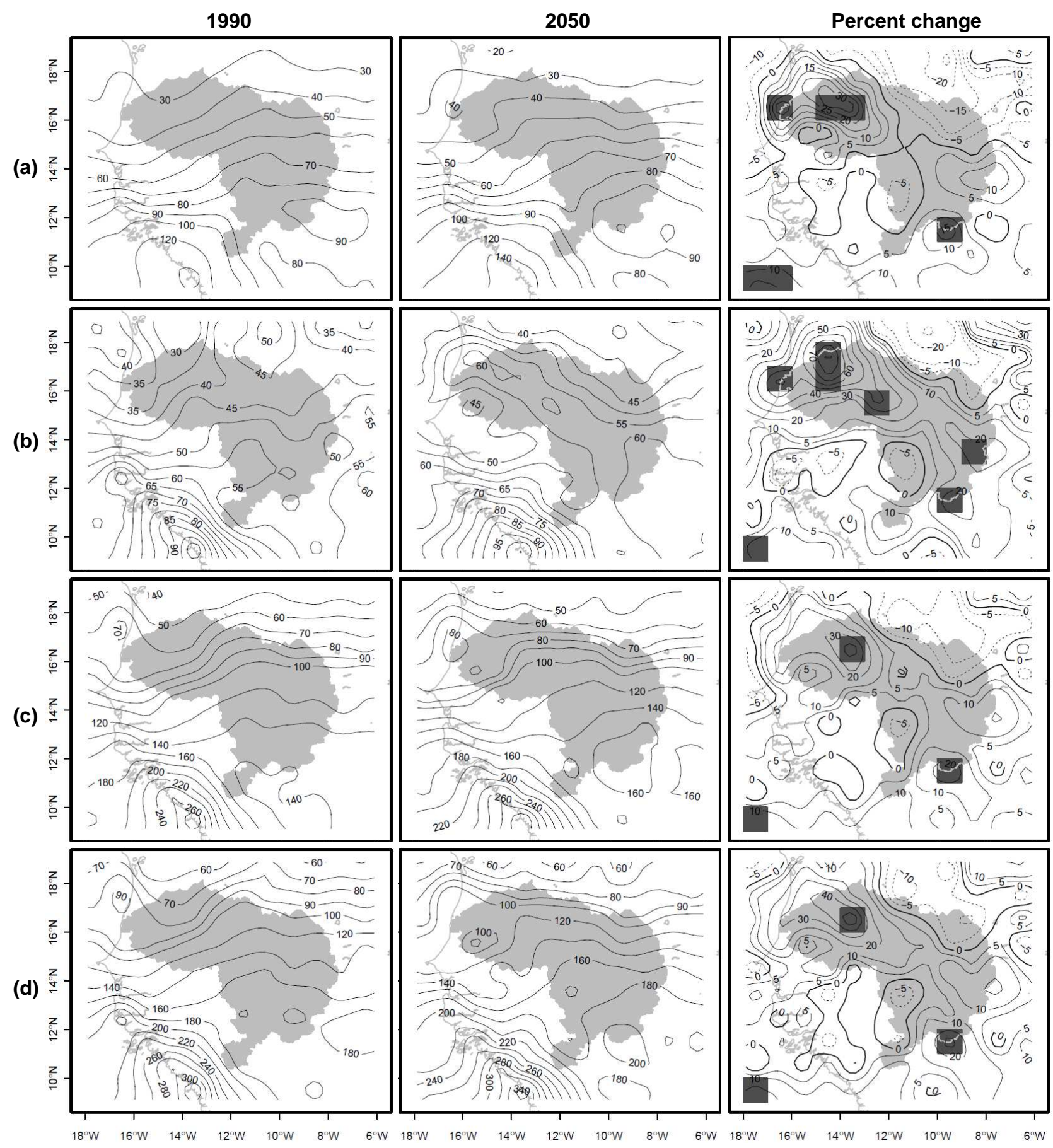

Fig. 5. Interpolated maps from the GAMLSS analysis for each site: (a) mean $\sigma$, (b) standard deviation $\sigma$; (c) associated with $T r=10 \mathrm{yr}$, and (d) $\operatorname{Tr}=20 \mathrm{yr}$. The maps for the years 1990 and 2050, and the percentage difference between them, are presented. In the difference maps, negative values are dashed, while the $95 \%$ confidence in projected changes is highlighted with the dark gray square.

for each site in the region based on the bias analysis, allowing the estimation of the spatio-temporal change of AMDR in the study area.

The use of weighted ensembles is justified by the fact that there are clear differences between the performance of the RCMs to simulate the present-day AMDR, where the best model may have nearly twice the skill score with respect to the worst model in some sites. However, the use of different weights affects the significance of the results. Several studies have addressed this issue, with the aim of designing more sophisticated methods for combining models. However, to know whether uncertainty in the evolution of future 
climate will remain at a similar level or whether it will be reduced substantially in the next decades, remains a challenge (Tebaldi and Knutti, 2007).

As key findings, from the interpolated maps various parameters of the PDF ensemble maintain the latitudinal gradient of rainfall in the area. However, in the difference maps for the reference years considered (1990 and 2050), this spatial pattern is not preserved. The percentage difference shows that in the Valley area, the increase of AMDR will be significantly higher than in the upper watershed area. In the Valley area, the increase in $\mu$ is projected to be more than $30 \%$ and the increase in $\sigma$ to be close to $80 \%$. Both increases will be reflected in the maximum precipitation amount for the $90 \%$ quantile, which will rise between $30-40 \%$ in the lower part of the basin, and for the $95 \%$ quantile, with a 40 $50 \%$ increase.

Future research lines will be to highlight the deeper analysis of robust and reproducible methods of estimation of skill scores associated with each RCM in the ensemble. With the aim of its application on spatio-temporal plausible patterns of other daily rainfall features (maximum dry spell lengths, annual or seasonal number of days without rainfall, etc.), and hydrometeorological variables (evaporation, temperatures, monthly rainfall) with implications in water resources management at basin scale. Even considering their application in regions with different hydroclimatic characteristics (such as the Mediterranean area). The ensemble procedure applied in this study should be compared with other proposals for calculating the weighting, in order to verify the spatial-temporal consistency of the methodological approach.

Another issue to take into account is whether the improvement in resolution of the models will affect the conclusions of the studies. Wehner et al. (2010) found that at high resolutions, the climatic models can produce precipitation values of comparable magnitude to high quality observations. However, at the resolutions typical of the coupled GCM, the precipitation is underestimated.

As it was shown, the future climate change will affect the frequency and intensity of natural hazards, such as extreme rain events, on Senegal River Basin. The impact on society depends on many factors, including the sequence and intensity of events, but also depends on the ability of the people to adapt and recover from the natural hazard. The knowledge and awareness about climate change by stakeholders is important.

In conclusion, a novel PDF ensemble approach was presented, which allows the identification of plausible spatial trends from continuously changing AMDR frequency distributions. The key findings of this study could be considered by OMVS, for designing and implementing effective adaptation strategies to climate variability and change in the region.

\section{Supplementary material related to this article is available online at: http://www.hydrol-earth-syst-sci.net/15/3605/2011/ hess-15-3605-2011-supplement.pdf.}

Acknowledgements. The support of the AMMA project is gratefully acknowledged. Based on a French initiative, AMMA was built by an international scientific group and is currently funded by a large number of agencies, especially from France, UK, US and Africa. It has been the beneficiary of a major financial contribution from the European Community's Sixth Framework Research Programme. Detailed information on scientific coordination and funding is available on the AMMA International web site http://www.amma-international.org. The authors acknowledge to IRD for providing observed daily rainfall.

Edited by: C. de Michele

\section{References}

Bark, R. H., Colby, B. G., and Dominguez, F.: Snow days? Snowmaking adaptation and the future of low latitude, high elevation skiing in Arizona, USA, Climatic Change, 102, 467-491, doi:10.1007/s10584-009-9708-x, 2010.

Boberg, F., Berg, P., Thejll, P., Gutowski, W. J., and Christensen, J. H.: Improved confidence in climate change projections of precipitation evaluated using daily statistics from the PRUDENCE ensemble, Clim. Dynam., 32, 1097-1106, 2009.

Boberg, F., Berg, P., Thejll, P., Gutowski, W. J., and Christensen, J. H.: Improved confidence in climate change projections of precipitation further evaluated using daily statistics from ENSEMBLES models, Clim. Dynam., 35, 1509-1520, 2010.

Buser, C. M., Künsch, H. R., Lüthi, D., Wild, M., and Schär C.: Bayesian multi-model projection of climate: bias assumptions and interannual variability, Clim. Dynam., 33, 849-868, doi:10.1007/s00382-009-0588-6, 2009.

Christensen, J. H., Rummukainen, M., and Lenderink, G.: Formulation of very-high-resolution regional climate model ensembles for Europe, in: ENSEMBLES: Climate change and its impacts at seasonal, decadal and centennial timescales: Summary of research and results from the ENSEMBLES project, edited by: van der Linden, P. and Mitchell, J. F. B., Met Office Hadley Centre, FitzRoy Road, Exeter EX1 3PB, UK, 47-58, 2009.

Cour, J. M.: The Sahel in West Africa: countries in transition to a full market economy, Global Environ. Change, 11, 31-47, 2001.

Diedhiou, A., Janicot, S., Viltard, A., de Félice, P., and Laurent, H.: Easterly waves regimes and associated convection over West Africa and the tropical Atlantic: Results from the NCEP/NCAR and ECMWF reanalyses, Clim. Dynam., 15, 795-822, 1999.

Dominguez, F., Cañón, J., and Valdes, J.: IPCC-AR4 climate simulations for the Southwestern US: the importance of future ENSO projections, Climatic Change, 99, 499-514, doi:10.1007/s10584009-9672-5, 2010.

Efron, B. and Tibshirani, R. J.: An introduction to the bootstrap, Chapman \& Hall, New York, NY, USA, 1993.

Fontaine, B., Roucou, P., and Monerie, P. A.: Changes in the African monsoon region at medium-term time horizon using 12 
AR4 coupled models under the A1b emissions scenario, Atmos. Sci. Lett., 12, 83-88, doi:10.1002/asl.321, 2011.

García Galiano, S. G. and Giraldo Osorio, J. D.: Analysis of impacts on hydrometeorological extremes in the Senegal River Basin from REMO RCM, Meteorol. Z., 19, 375-384, 2010.

García Galiano, S. G. and Giraldo Osorio, J. D.: Non-stationary analysis of spatial patterns of extreme rainfall events in West Africa, in: Hydro-climatology: Variability and Change (Proceedings of IAHS Lead Symposia held during IUGG2011 in Melbourne, Australia, July 2011), IAHS Publ. 344, IAHS Press, CEH Wallingford, Oxfordshire, United Kingdom, 75-81, 2011.

Giorgi, F.: A Simple Equation for Regional Climate Change and Associated Uncertainty, J. Climate, 21, 1589-1604, doi:10.1175/2007JCLI1763.1, 2008.

Giorgi, F. and Mearns, L. O.: Calculation of average, uncertainty range, and reliability of regional climate changes from AOGCM simulations via the "reliability ensemble averaging" (REA) method, J. Climate, 15, 1141-1158, 2002.

Giorgi, F. and Mearns, L. O.: Probability of regional climate change based on reliability ensemble averaging (REA) method, Geophys. Res. Lett., 30, 311-314, doi:10.1029/2003GL017130, 2003.

Huntington, T. G.: Evidence for intensification of the global water cycle: review and synthesis, J. Hydrol., 319, 83-95, 2006.

Janicot, S. and Sultan, B.: Intra-seasonal modulation of convection in the West African monsoon, Geophys. Res. Lett., 28, 523-526, 2001.

Karambiri, H., García, S. G., Giraldo, J. D., Yacouba, H., Ibrahim, B., Barbier, B., and Polcher, J.: Assessing the impact of climate variability and climate change on runoff in West Africa: the case of Senegal and Nakambe River basins, Atmos. Sci. Let., 12, 109115, doi:10.1002/asl.317, 2011.

Kharin, V. V. and Zwiers, F. W.: Estimating Extremes in Transient Climate Change Simulations, J. Climate, 18, 1156-1173, 2005.

Kharin, V. V., Zwiers, F. W., Zhang, X., and Hegerl, G. C.: Changes in Temperature and Precipitation Extremes in the IPCC Ensemble of Global Coupled Model Simulations, J. Climate, 20, 14191444, doi:10.1175/JCLI4066.1, 2009.

Kyselý, J. and Beranová, R.: Climate-change effects on extreme precipitation in central Europe: uncertainties of scenarios based on regional climate models, Theor. Appl. Climatol., 95, 361-374, doi:10.1007/s00704-008-0014-8, 2009.

Kundzewicz, Z. W., Mata, L. J., Arnell, N. W., Döll, P., Kabat, P., Jiménez, B., Miller, K. A., Oki, T., Sen, Z., and Shiklomanov, I. A.: Freshwater resources and their management. In Climate Change 2007: Impacts, Adaptation and Vulnerability. Contribution of Working Group II to the Fourth Assessment Report of the Intergovernmental Panel on Climate Change, edited by: Parry, M. L., Canziani, O. F., Palutikof, J. P., van der Linden, P. J., and Hanson, C. E., 173-210, Cambridge University Press, Cambridge, UK, 2007.

Labat, D., Goddéris, Y., Probst, J. L., and Guyot, J. L.: Evidence for global runoff increase related to climate warming, Adv. Water Resour., 27, 631-642, 2004.

Lebel, T., Cappelaere, C., Galle, S., Hanan, N., Kergoat, L., Levis, L., Vieux, B., Descroix, L. Gosset, M., Mougin, E., Peugeot, C., and Seguis, L.: AMMA-CATCH studies in the Sahelian region of West-Africa: an overview, J. Hydrol., 375, 3-13, 2009.

Messager, G., Gallée, H., and Brasseur, O.: Precipitation sensitivity to regional SST in a regional climate simulation during the West African monsoon for two dry years, Clim. Dynam., 22, 249-266, 2004.

Milly, P. C. D., Betancourt, J., Falkenmark, M., Hirsch, R. M., Kundzewicz, Z. W., Lettenmaier, D. P., and Stouffer, R. J.: Stationarity is dead: Whither water management?, Science, 319, 573-574, 2008.

Mote, P. W. and Salathé, E. P.: Future climate in the Pacific Northwest, Climatic Change, 102, 29-50, doi:10.1007/s10584-0109848-z, 2010.

Nikulin, G., Kjellström, E., Hansson, U., and Strandberg, G.: Evaluation and future projections of temperature, precipitation and wind extremes over Europe in an ensemble of regional climate simulations, Tellus, 63 A, 41-55, doi:10.1111/j.16000870.2010.00466.x, 2011.

Paeth, H., Born, K., Girmes, R, Podzun, R., and Jacob, D.: Regional climate change in tropical and northern Africa due to greenhouse forcing and land use changes, J. Climate, 22, 114-132, 2009.

Paeth, H., Hall, N. M. J., Gaertner, M., Alonso, M. D., Moumouni, S., Polcher, J., Ruti, P. M., Fink, A. H., Gosset, M., Lebel, T., Gaye, A. T., Rowell, D. P., Moufouma-Okia, W., Jacob, D., Rockell, B., Giorgi, F., and Rummukainen, M.: Progress in regional downscaling of West African precipitation, Atmos. Sci. Let., 12, 75-82, doi:10.1002/asl.306, 2011.

Perkins, S. E. and Pitman, A. J.: Do weak AR4 models bias projections of future climate changes over Australia?, Climatic Change, 93, 527-558, 2009.

Perkins, S. E., Pitman, A. J., Holbrook, N. J., and McAneney, J.: Evaluation of the AR4 climate models' simulated daily maximum temperature, minimum temperature, and precipitation over Australia using probability density functions, J. Climate, 20, 4356-4376, 2007.

Räisänen, J., Ruokolainen, L., and Ylhäisi, J.: Weighting of model results for improving best estimates of climate change, Clim. Dynam., 35, 407-422, doi:10.1007/s00382-009-0659-8, 2010.

Ruti, P. M., Williams, J. E., Hourdin, F., Guichard, F., Boone, A., Van Velthoven, P., Favot, F., Musat, I., Rummukainen, M., Domínguez, M., Gaertner, M. Á., Lafore, J. P., Losada, T., Rodriguez de Fonseca, M. B., Polcher, J., Giorgi, F., Xue, Y., Bouarar, I., Law, K., Josse, B., Barret, B., Yang, X., and Mari, C.: The West African climate system: a review of the AMMA model inter-comparison initiatives, Atmos. Sci. Let., 12, 116122, doi:10.1002/asl.305, 2011.

Rigby, R. A. and Stasinopoulos, D. M.: Generalized additive models for location scale and shape, Appl. Stat., 54, 507-554, 2005.

Sánchez, E., Romera, R., Gaertner, M. A., Gallardo, C., and Castro, M.: A weighting proposal for an ensemble of regional climate models over Europe driven by 1961-2000 ERA40 based on monthly precipitation probability density functions, Atmos. Sci. Lett., 10, 241-248, 2009.

Sandholt, I., Andersen, J., Dybkjær, G., Nyborg, L., Lô, M., Rasmussen, K., Refsgaard, J. C., and Touré, A.: Integration of earth observation data in distributed hydrological models: the Senegal River basin, Can. J. Remote Sens., 29, 701-710, 2003.

Smith, I. and Chandler, E.: Refining rainfall projections for the Murray Darling Basin of south-east Australia-the effect of sampling model results based on performance, Climatic Change, 102, 377-393, 2010.

Stasinopoulos, D. M. and Rigby, R. A.: Generalized additive mod- 
els for location scale and shape (GAMLSS) in: R., J. Stat. Software, 23, 1-46, 2007.

Sylla, M. B., Gaye, A. T., Pal, J. S., Jenkins, G. S, and Bi, X. Q.: High-resolution simulations of West African climate using regional climate model (RegCM3) with different lateral boundary conditions, Theor. Appl. Climatol., 98, 293-314, doi:10.1007/s00704-009-0110-4, 2009.

Sylla, M. B., Coppola, E., Mariotti, L., Giorgi, F., Ruti, P. M., Dell'Aquila, A., Bi, X.: Multiyear simulation of the African climate using a regional climate model (RegCM3) with the high resolution ERA-interim reanalysis, Clim. Dynam., 35, 231-247, doi:10.1007/s00382-009-0613-9, 2010a.

Sylla, M. B., Dell'Aquila, A., Ruti, P. M., Giorgi, F.: Simulation of the intraseasonal and the interannual variability of rainfall over West Africa with RegCM3 during the monsoon period, Int. J. Climatol., 30, 1865-1883, doi:10.1002/joc.2029, 2010 b.

Tapiador, F. J., Sánchez, E., and Romera, R.: Exploiting an ensemble of regional climate models to provide robust estimates of projected changes in monthly temperature and precipitation probability distribution functions, Tellus, $61 \mathrm{~A}, 57-71$, doi:10.1111/j.1600-0870.2008.00374.x, 2009.

Tebaldi, C. and Knutti, R.: The use of the multi-model ensemble in probabilistic climate projections, Phil. T. Roy. Soc. A, 365, 2053-2075, doi:10.1098/rsta.2007.2076, 2007.
Tebaldi, C., Smith, R. L., Nychka, D., and Mearns, L. O.: Quantifying Uncertainty in Projections of Regional Climate Change: A Bayesian Approach to the Analysis of Multimodel Ensembles, J. Climate, 18, 1524-1540, 2005.

van Buuren, S. and Fredriks, M.: Worm plot: a simple diagnostic device for modelling growth reference curves, Statist. Med., 20, 1259-1277, 2001.

Villarini, G., Smith, J. A., Serinaldi, F., Bales, J., Bates, P. D., and Krajewski, W. F.: Flood frequency analysis for nonstationary annual peak records in an urban drainage basin, Adv. Water Res, 32, 1255-1266, 2009.

Villarini, G., Smith, J. A., and Napolitano, F.: Nonstationary modeling of a long record of rainfall and temperature over Rome, Adv. Water Res, 33, 1256-1267, 2010.

Wehner, M. F., Smith, R. L., Bala, G., and Duffy, P.: The effect of horizontal resolution on simulation of very extreme US precipitation events in a global atmosphere model, Clim. Dynam., 34, 241-247, doi:10.1007/s00382-009-0656-y, 2010.

Wigley, T. M. L. and Raper, C. B.: Interpretation of high projections for global-mean warming, Science, 293, 451-454, 2001. 